\title{
Post mortem coronary angiography in a preemie heart - a case report
}

\author{
Amna Qasim ${ }^{1 *}$ (D) Duraisamy Balaguru² and Ashraf M. Aly ${ }^{3}$
}

\begin{abstract}
Background: Postmortem coronary angiography has been used in forensic medicine for several decades but its use has never been documented in neonatal hearts. The objective of this case is to report the use of postmortem coronary angiography as a diagnostic modality for neonates suspected to have complex congenital heart anomalies.

Case presentation: A 36-week-old female infant required extracorporeal membranous oxygenation for persistent hypotension on day 1 of life. A congenital echocardiogram (ECHO) on day 3 of life revealed multiple anomalous vascular structures within the interventricular septum. The infant passed away on day 4 of life after the parents elected to withdraw support. A consent for autopsy was taken from the parents and a postmortem coronary angiography was performed. The coronary vessels were injected with lodixanol contrast via a $24 \mathrm{G}$ angiocath under fluoroscopy. The anomalous septal vessels were identified as dilated coronary artery and vein. No other anomalies were identified.
\end{abstract}

Conclusion: Postmortem coronary angiography complements other imaging procedures in understanding the nature of some complex congenital heart defects and in determining the cause of death in such neonates.

Keywords: Pediatric cardiology, Coronary angiography, Cardiac pathology, Diagnostic imaging, Forensic pathology

\section{Introduction}

What is already known about this subject?

Coronary angiography is a well-known modality in the pediatric and adult cardiology would.

\section{What does this study add?}

The use of coronary angiography as a tool in postmortem examination/autopsies of neonatal hearts has not been documented in the past; It can be a useful tool in helping understand complex congenital heart disease.

\section{How might this impact on clinical practice?}

Post mortem coronary angiography can be an adjunct to other diagnostic imaging modalities in postmortem examinations to help improve our understanding of complex congenital heart lesions.

\section{Background}

Postmortem examinations are vital for the understanding of some complex cardiac lesions that may not be

\footnotetext{
* Correspondence: amqasim@utmb.edu; amnahqasim@gmail.com

${ }^{1}$ University of Texas Medical Branch, 301 University Blvd, Galveston TX-77555, USA

Full list of author information is available at the end of the article
}

clearly seen by echocardiography (ECHO). With the recent advances in science, many institutions are performing postmortem CT angiography routinely for cases with sudden death $[1,2]$. Postmortem coronary angiography has been utilized in forensic medicine for several decades [3]. It helps to ascertain unusual anatomic variations like aneurysms and anastomoses. We report a case of postmortem coronary angiography performed on a neonatal heart.

\section{Case presentation}

A $2080 \mathrm{~g}$ female infant was born at 36 weeks via C-section due to fetal distress. The pregnancy was complicated by intrauterine growth retardation, suspected fetal arrhythmia, abnormal fetal ultrasound (suspected Ebstein's anomaly of the tricuspid valve), multiple maternal viral syndromes and poor prenatal care (late entry into the United States at 31 weeks' gestation, prior care in El Salvador). Apgar scores were $1,3,4$ at 1,5 , and $10 \mathrm{~min}$, respectively. Despite adequate ventilation and fluid resuscitation, the infant remained hypotensive and had profound metabolic acidosis (arterial $\mathrm{pH}$ of 6.56). Prostaglandins were started in addition to inotropes. Echocardiogram (ECHO) in the first few hours of life revealed a poor left ventricular function (shortening

(c) The Author(s). 2019 Open Access This article is distributed under the terms of the Creative Commons Attribution 4.0 International License (http://creativecommons.org/licenses/by/4.0/), which permits unrestricted use, distribution, and 
fraction of $11.8 \%)$, a severe biventricular hypertrophy and a moderate size patent ductus arteriosus (PDA) with a bidirectional shunt. There was a moderate to severe tricuspid regurgitation (peak gradient of $75 \mathrm{mmHg}$ ) with severe pulmonary hypertension (estimated right ventricular pressure of 80 $\mathrm{mmHg}$ ). Otherwise normal four chamber intra-cardiac anatomy. The infant was placed on veno-arterial extracorporeal membranous oxygenation (ECMO) at $6 \mathrm{~h}$ of life. A repeat $\mathrm{ECHO}$ on the third day of life showed improved LV function (SF 25\%), severe pulmonary hypertension (estimated right ventricular pressure of $90 \mathrm{mmHg}$ ), a small apical muscular ventricular septal defect (VSD) with a right to left and multiple vascular structures within the ventricular septum (Fig. 1, Additional file 1: Video S1). These structures were suspected to be coronary fistulas, dilated coronary vessels or unusual VSD tracts within the ventricular septum [4]. The infant subsequently developed a grade 4 intraventricular hemorrhage and passed away on the fourth day of life. Work up for common infectious causes of congenital infections was negative. Genetic evaluation revealed a normal $46 \mathrm{XX}$ karyotype and a negative cardiomyopathy panel.

\section{Autopsy}

Due to the ambiguity of the vascular structures in the $\mathrm{ECHO}$, a consent for an autopsy was obtained from the parents. The autopsy showed severe biventricular hypertrophy, a small apical muscular VSD and a dilated left main left anterior descending (LAD) coronary arteries. Otherwise, the gross anatomy of the heart was normal (Fig. 2a).

\section{Post-mortem coronary angiography}

During the initial autopsy examination, the ventricular cavities were opened by para-septal incisions and the origin of the LAD was severed. Therefore, the LAD was cannulated with a 24 G Angiocath (Fig. 2a). Initially, a $5 \mathrm{ml}$ of normal saline was injected to clear the coronary artery from blood clots. An oozing of saline from the cut surface of the myocardium into both ventricle was noted. Then, $0.3 \mathrm{ml}$ of Iodixanol (Visipaque 320, GE Healthcare) contrast was injected in the LAD and an angiogram was obtained (Fig. 2b). This showed a normal branching pattern of the distal LAD without any evidence of fistulous drainage into the LV apex. Because of the damage of LAD during the autopsy, we decided to inject contrast into the coronary sinus to delineate the coronary venous anatomy. The coronary sinus was cannulated and the catheter was advanced to the middle coronary vein where a $0.3 \mathrm{ml}$ of Iodixanol contrast was injected. The middle coronary vein was remarkably dilated and its tributaries opacified and there was also a late opacification of distal branches of LAD (Fig. 3). This further confirmed that there were no abnormal coronary venous structures or fistulas that may have been missed in the prior angiogram of the LAD.

Based on these images, it was concluded that the prominent coronary artery and vein were secondary to

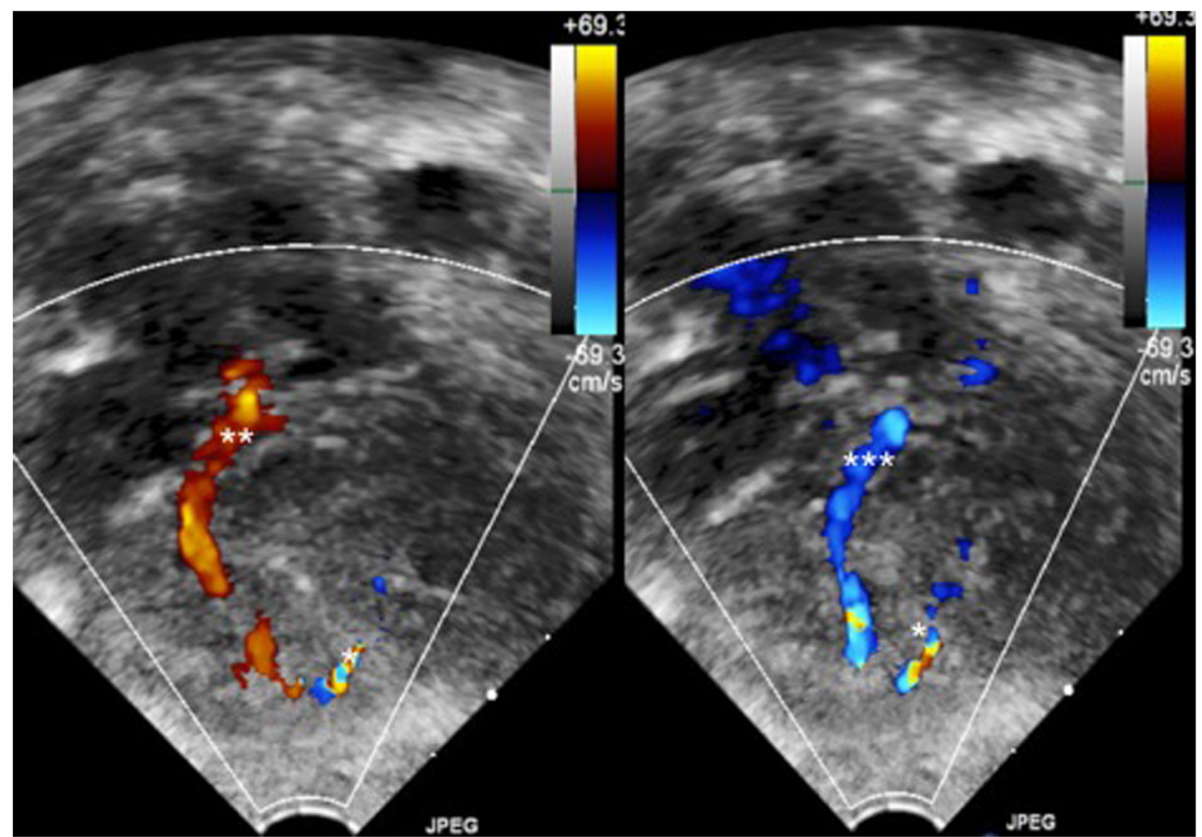

Fig. 1 Echocardiographic images of Apical 4 chamber view showing VSD with right to left shunt $\left(^{*}\right)$, prominent coronary artery $\left({ }^{*}\right)$ and prominent coronary vein $\left(^{* * *}\right)$ 


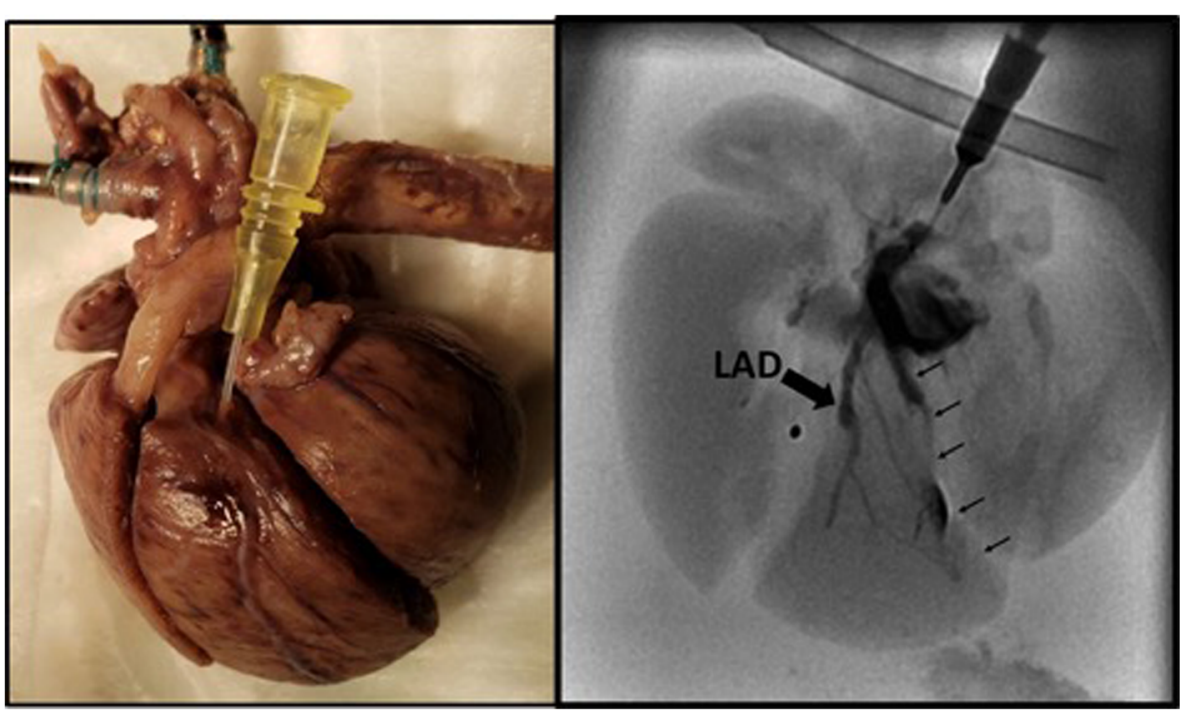

Fig. 2 Panel A shows cannulation of LAD using a 24 gauge Angiocath ${ }^{\oplus}$. The origin of LAD was cut when the para-septal incision was made to open the LV. It is suggested that coronary angiogram is better performed before any incisions are made in the heart specimen. Panel B: Angiogram of LAD showing normal branches without evidence of coronary fistula (block arrow). There is some additional opacities from seepage of radiographic contrast from the cut-surfaces of the myocardium on either sides of the ventricular septum (thin arrows)

severe ventricular hypertrophy. There was no evidence of a coronary fistula.

\section{Discussion \& Conclusions}

To our knowledge, this is the first report of postmortem coronary angiography on a neonatal heart. This study highlights

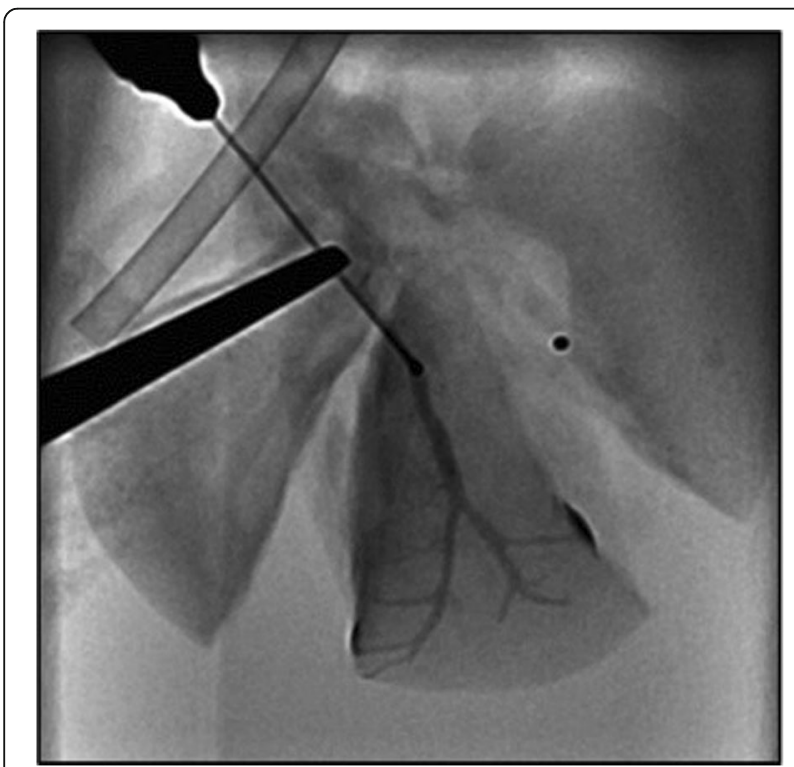

Fig. 3 Angiogram of middle cardiac vein. The coronary sinus was cannulated retrograde. Tip of the probe is in middle cardiac vein and retrograde filling of the middle cardiac vein was performed to look for coronary fistula or coronary arterio-venous connection. This imaging shows normal middle cardiac vein the significance of a collaborative effort between cardiology and pathology in answering questions for neonates with an unclear cause of death or complex congenital cardiac anomalies especially if the patient is not stable enough before death to go through a cardiac MRI or catheterization.

Several contrast media have been used for postmortem angiography. These include corpuscular radiopaque contrast materials (lead oxide and barium sulfate), oily liquids (paraffin oil, diesel oil), hydrosoluble preparations (Gastrograffin, cardiografin) and Casts (silicon rubber-lead oxide) with each associated with its own pros and cons [3]. One study suggested the use of colored dyes mixed with Gastrograffin and using different colors for the right and left coronary arteries in order to help with delineation during subsequent macroscopic and microscopic examinations [5]. We used Iodixanol (Visipaque 320), a contrast agent commonly used in coronary angiography due to its favorable properties [6].

We describe a methodology for performing postmortem coronary angiography in neonatal heart specimen. We recommend that angiograms be performed prior to dissection of the heart to maintain the integrity of the coronary arteries that can facilitate cannulation and injection of contrast. This procedure may complement other imaging procedures in understanding the nature of some complex congenital heart defects and in determining the cause of death.

\section{Additional file}

Additional file 1: Video S1. Echocardiogram in apical 4 chamber view showing prominent vascular structures in the interventricular septum (blue venous flow and red arterial flow) and a small VSD with a right to left shunt. 


\section{Abbreviations}

CT: Computed tomography; ECHO: Echocardiography; ECMO: Extracorporeal membranous oxygenation; G: Gauge; LAD: Left anterior descending; LV: Left ventricular; VSD: Ventricular septal defect

\section{Acknowledgements}

Not applicable.

\section{Authors' contributions}

AA made the initial patient diagnosis, DB helped in performing the postmortem coronary angiography. AQ collected all the data and was a major contributor in writing the manuscript. All authors read and approved the final manuscript

\section{Funding}

None

\section{Availability of data and materials}

Not applicable.

\section{Ethics approval and consent to participate}

Ethics approval was obtained from the institution prior to performing the autopsy. Since this was a case report without any identifying information, an IRB approval was not required.

\section{Consent for publication}

Consent for publication was obtained from the parents of the patient (neonate) verbally and a written consent was obtained for the autopsy/postmortem coronary angiography.

\section{Competing interests}

The authors declare that they have no competing interests.

\section{Author details}

'University of Texas Medical Branch, 301 University Blvd, Galveston TX-77555, USA. ${ }^{2}$ Dept of Pediatrics, Division of Pediatric Cardiology, University of Texas Health Science Center, Houston, TX, USA. ${ }^{3}$ Division of Pediatric Cardiology, University of Texas Medical Branch, Galveston, TX, USA.

Received: 24 June 2019 Accepted: 28 October 2019

Published online: 18 December 2019

\section{References}

1. Arrive L, Pichereau C, Monnier-Cholley L, Bourcier S, Phan C, Maury E. Postmortem coronary CT angiography. Intensive Care Med. 2016;42(8):1293.

2. Heinemann A, Mullerleile K, Chevalier C, Grabherr S, Vogel H. Postmortem enhancement of coronary arteries by multiphase whole body CT angiography. Comparison with antemortem coronary angiography. Rechtsmedizin. 2014;24(2):107-13.

3. Grabherr S, Djonov V, Yen K, Thali MJ, Dirnhofer R. Postmortem angiography: review of former and current methods. Am J Roentgenol. 2007;188(3):832-8.

4. Dasgupta S, Aly AM. An Unusual Mechanism of Closure of Muscular Ventricular Septal Defects. Case Rep Pediatr. 2017;2017:4303298.

5. Smith M, Trummel DE, Dolz M, Cina SJ. A simplified method for postmortem coronary angiography using gastrograffin. Arch Pathol Lab Med. 1999;123(10):885-8.

6. Almen T. Visipaque - a step forward: a historical review. Acta Radiol. 2016; 57(5):E47-63.

\section{Publisher's Note}

Springer Nature remains neutral with regard to jurisdictional claims in published maps and institutional affiliations.

Ready to submit your research? Choose BMC and benefit from:

- fast, convenient online submission

- thorough peer review by experienced researchers in your field

- rapid publication on acceptance

- support for research data, including large and complex data types

- gold Open Access which fosters wider collaboration and increased citations

- maximum visibility for your research: over $100 \mathrm{M}$ website views per year

At BMC, research is always in progress.

Learn more biomedcentral.com/submissions 